accepted the need for such restrictions; these are now being introduced in stages which should result in the stocks starting to build up in 1968. If these first steps towards rational conservation can be kept up, future years should see both thriving stocks of whales and continued substantial supplies of oil and other products for a hungry world.

JOHN GULLAND

\title{
Whales, Dolphins and Porpoises, edited by Kenneth S. Norris. University of California Press. \$15.00.
}

The whales can no longer be regarded as the world's least-known mammals. During the last sixty years whaling has become a vast industry of great economic importance, and at last those engaged in whaling have realised that the biology of their quarry must be known if the industry is to survive. To this end they have given facilities, both directly in their ships and shore installations, and indirectly through taxation to finance research, that have put a great store of knowledge at their disposal. It seems incredible that they have ignored the resulting scientific advice, and have destroyed their own once lucrative industry. Today the few firms that remain in whaling are ruthlessly pursuing their victims, in order to recover the enormous capital invested before the stocks of whales are so reduced that it will no longer pay to hunt them. We can, however, expect that the industry will become extinct before the whales, which may, if left alone for a century, recover something of their numbers, so that they can be rationally exploited by posterity if it will but learn the lessons of the past.

This volume contains the papers, and the discussions that they stimulated, given at the First International Symposium on Cetacean Research held at Washington, DC, in August 1963. They form a comprehensive cross-section of the science of cetology at that date, and their contents show how rapidly knowledge is advancing in this branch of zoology.

The smaller cetaceans, dolphins and porpoises, have recently become available for close study by zoologists through the invention of huge aquaria where trained dolphins perform tricks for public amusement. An unintended offshoot of these marine circuses has been the experimental work that scientists have been able to carry out on the inmates, which has revealed a whole range of new facts about the physiology of the cetacea. One of the most striking discoveries is the system of echo-location or sonar, which enables the animals, in turbid water or at night, to locate small prey and other objects at a distance. The biology of the dolphins, now being so intensively studied, will no doubt give information of the utmost use to man in his penetration of the ocean depths, a project which is likely to be much more rewarding than his attempts to penetrate into space.

The papers of this symposium range widely, from systematics, anatomy and physiology to communication, sonar, and behaviour. All by specialists, and most of them highly technical, they form a valuable and stimulating source-book for all who work on problems of cetology. I have sat through many symposia, but $I$ have never attended one so full of originality and intellectual cross-fertilization, or so enjoyable, as was this. The volume is very well produced, printed and illustrated. Cetologists all over the world are greatly indebted to the American Institute of Biological Sciences which organised the symposium and secured financial help for it through the Office of Naval Research.

L. HARRISON MATTHEWS 